\title{
PENGARUH MODEL PEMBELAJARAN KOOPERATIF TIPE STAD BERBANTUAN MEDIA AUDIO VISUAL TERHADAP HASIL BELAJAR FISIKA SISWA KELAS XI SMA NEGERI 1 TIKKE RAYA
}

\author{
Riska, Syamsu, dan Marungkil Pasaribu \\ Jurusan Pendidikan MIPA \\ Fakultas Keguruan dan IImu Pendidikan Universitas Tadulako Palu
}

\begin{abstract}
Abstrak-Tujuan penelitian adalah untuk mengetahui ada tidaknya pengaruh model pembelajaran kooperatif tipe STAD berbantuan media audio visual terhadap hasil belajar fisika siswa kelas XI di SMAN 1 Tikke Raya. Jenis penelitian ini merupakan eksperimen kuasi dengan equivalent pretest-posttest design. Populasi penelitian ini adalah seluruh siswa kelas XI SMA Negeri 1 Tikke Raya. Teknik Sampling yang digunakan dalam penelitian ini adalah Proposive Sampling dengan sampel penelitian adalah kelas XI IPA 1 sebagai kelompok kontrol dan kelas XI IPA 2 sebagai kelompok eksperimen. Instrumen hasil belajar fisika berupa tes pilihan ganda yang telah divalidasi melalui validitas kontruksi. Tes hasil belajar fisika yang diperoleh menunjukkan bahwa skor rata-rata kelompok eksperimen 17,93 dengan standar deviasi 2,81 dan skor rata-rata kelompok kontrol 16,76 dengan standar deviasi 2,57. Dari hasil analisa data tes akhir diperoleh nilai table untuk $n=35$ pada taraf nyata $\alpha=0,05$ dan $d k=68$ adalah 1,67 dan nilai

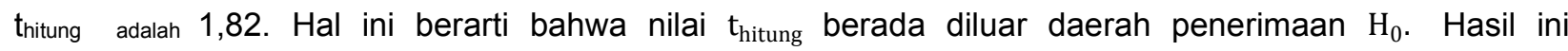
menyatakan terdapat perbedaan hasil belajar kelas yang diterapkan model pembelajaran kooperatif tipe STAD berbantuan media audio visual dengan kelas yang diterapkan model pembelajaran langsung. Dengan demikian dapat disimpulkan bahwa terdapat pengaruh model pembelajaran kooperatif tipe STAD berbantuan media audio visual terhadap hasil belajar fisika siswa kelas XI SMAN 1 Tikke Raya.
\end{abstract}

Kata Kunci: kooperatif tipe STAD, media audio visual, hasil belajar

\section{PENDAHULUAN}

Guru berperan sangat penting dalam kegiatan pembelajaran, karena guru bertanggungjawab terhadap tujuan pembelajaran yang ingin dicapai secara optimal. Selain sebagai tenaga pendidik dan pengajar, tugas utama guru di sekolah adalah sebagai fasilitator sekaligus motivator.

Guru harus dapat memilih model pembelajaran yang tepat dan berorientasi pada peningkatan intensitas keterlibatan siswa secara aktif sehingga dapat memotivasi siswa untuk belajar lebih giat agar mendapat hasil belajar yang optimal. Pemilihan model pembelajaran yang tepat tersebut memiliki keterkaitan dengan tingkat pemahaman guru terhadap perkembangan dan kondisi siswa di kelas. Tanpa pemahaman terhadap kondisi ini, model yang dikembangkan guru cenderung tidak dapat meningkatkan peran siswa secara aktif dalam pembelajaran dan pada akhirnya tidak dapat memberi sumbangan yang besar terhadap pencapaian hasil belajar siswa. Oleh karena itu, guru harus jeli memilih model pembelajaran yang efektif dan dapat menerapkan variasi model dalam kegiatan pembelajaran untuk meningkatkan peran aktif siswa sehingga hasil belajar yang diinginkan dapat tercapai.

Menurut Sharan [1] salah satu alternatif untuk menciptakan kinerja siswa adalah dengan menerapkan model pembelajaran kooperatif. Pembelajaran kooperatif adalah model pembelajaran yang memberikan kesempatan bagi siswa untuk mengembangkan keterampilan dan pengetahuan dalam interaksi kelompok dan kerja tim.

Menurut Johnson [2] pembelajaran kooperatif menekankan interaksi teman sebaya dan pembelajaran kelompok melalui interpedensi sosial dimana input dari individu membawa pemahaman yang efektif tentang keseluruhan struktural dan bukan hanya sebagian.

Menurut Wibowo [3] model pembelajaran kooperatif tipe STAD merupakan model kooperatif yang menekankan pada aktivitas dan interaksi diantara siswa untuk saling membantu dalam menguasai materi pelajaran guna mencapai prestasi yang maksimal. Pembelajaran kooperatif tipe STAD merupakan pembelajaran kooperatif dengan menggunakan kelompok-kelompok kecil dengan jumlah anggota tiap kelompok 4-5 orang siswa secara heterogen yang diawali dengan penyampaian tujuan pembelajaran, penyampaian materi, kegiatan kelompok, kuis dan penghargaan kelompok.

Isjoni [4] menjelaskan model pembelajaran kooperatif tipe STAD dapat melatih siswa dalam mengembangkan aspek kecakapan sosial di samping kecakapan kognitif dan peran guru juga menjadi lebih aktif serta lebih terfokus sebagai fasilitator, mediator, motivator dan evaluator.

Sedangkan Herdian [5] berpendapat bahwa model pembelajaran kooperatif tipe STAD mempunyai beberapa keunggulan, yaitu semua anggota kelompok wajib mendapat tugas, siswa 
dilatih untuk mengembangkan keterampilan sosial, mendorong siswa untuk menghargai pendapat orang lain, dapat meningkatkan kemampuan akademik siswa dan melatih siswa untuk berani bicara di depan kelas.

Penelitian sebelumnya yang dilakukan oleh Nuryanti, dkk [6] mengemukakan bahwa penerapan model STAD sesuai karakteristiknya dan dikemas dalam skenario pembelajaran yang tepat pada pembelajaran matematika dapat meningkatkan hasil belajar siswa secara optimal yang ditunjukkan melalui tes hasil belajar siswa.

Selain model pembelajaran kooperatif tipe STAD, media pembelajaran juga mempengaruhi keberhasilan proses pembelajaran di dalam kelas, terutama dalam memberikan pemahaman terhadap peserta didik tentang materi yang diajarkan. Terdapat banyak media pembelajaran yang digunakan oleh guru, salah satunya adalah media audio visual dalam bentuk video.

Video merupakan salah satu bentuk media pembelajaran audio visual yang mampu menumbuhkan minat dan motivasi belajar siswa sehingga berpengaruh pada hasil belajar siswa. Media audio visual merupakan intruksional modern yang sesuai dengan perkembangan zaman, meliputi media yang dapat dilihat dan didengar [7].

Menurut Ibrahim [8] video merupakan penayangan ide atau gagasan pada layar televisi sesuai dengan kata video yang dalam bahasa latin berarti "saya melihat".

Kegiatan pembelajaran, sangat baik jika digunakan media audio visual sebagai perantara menyampaikan pembelajaran dari guru kepada siswa. Model pembelajaran kooperatif tipe STAD berbantuan media audio visual sesuai dengan proses pembelajaran IPA. Hal ini karena model pembelajaran kooperatif tipe STAD berbantuan media audio visual dapat menggali potensi siswa untuk saling bekerja sama atau belajar secara berkelompok terutama dalam memberikan informasi atau pesan dari kelompok satu ke kelompok lainnya.

Selain itu kooperatif tipe STAD juga memberikan peluang kepada siswa untuk berpartisipasi aktif berdiskusi dalam proses pembelajaran sehingga dengan penggunaan model pembelajaran kooperatif tipe STAD berbantuan media audio visual menggunakan presentasi video dapat menciptakan kreativitas dan kerjasama siswa agar pembelajaran dikelas menjadi lebih efektif, maka siswa nantinya diharapkan lebih memahami materi sehingga hasil belajar lebih meningkat.

Tujuan penelitian ini yaitu untuk mengetahui pengaruh model pembelajaran kooperatif tipe STAD berbantuan media audio visual terhadap hasil belajar fisika siswa kelas XI SMAN 1 Tikke Raya.

Manfaat penelitian ini yaitu diharapkan dapat memberi sumbangan ilmu pengetahuan dan pendidikan serta dapat menjadi bahan referensi untuk penelitian selanjutnya.

\section{METODE PENELITIAN}

Jenis penelitian yang digunakan dalam penelitian ini adalah penelitian kuasi eksperimen. Adapun desain penelitian yang digunakan yaitu equivalent pretest-posttest design, yang diartikan sebagai rancangan pratest-pascates yang ekuivalen dengan memilih kelas-kelas yang diperkirakan sama keadaan/kondisinya, dalam hal ini sama berdasarkan tingkat kecerdasan. Dimana satu kelas yang berfungsi sebagai kelas eksperimen dan satu kelas berfungsi sebagai kelas kontrol.

TABEL 1 EQUIVALEN PRETEST- POSTEST DESIGN

\begin{tabular}{lccc}
\hline \multicolumn{1}{c}{ Kelompok } & Pre -Test & Perlakuan & Post -Test \\
\hline A (eksperimen) & $\mathrm{O}_{1}$ & $\mathrm{X}_{1}$ & $\mathrm{O}_{2}$ \\
\hline $\mathrm{B}$ (kontrol) & $\mathrm{O}_{1}$ & - & $\mathrm{O}_{2}$ \\
\hline
\end{tabular}

Keterangan:

$\begin{array}{ll}\mathrm{A} & \text { : Kelompok eksperimen } \\ \mathrm{B} & \text { : Kelompok kontrol } \\ \mathrm{X}_{1} & : \text { Model Pembelajaran Kooperatif Tipe STAD berbantuan Media Audio Visual } \\ \mathrm{O}_{1} & : \text { Tes awal (preetest) } \\ \mathrm{O}_{2} & : \text { Tes akhir (postest) }\end{array}$

Penelitian ini dilaksanakan di SMA Negeri 1 Tikke Raya pada kelas XI di semester ganjil tahun pelajaran 2018. Populasi pada penelitian ini yaitu seluruh siswa kelas XI IPA SMA Negeri 1 Tikke Raya. Sampel yang digunakan yaitu kelas XI IPA 2 berjumlah 35 siswa untuk kelas eksperimen dan kelas XI IPA 1 berjumlah 35 siswa untuk kelas kontrol. Pengambilan sampel dilakukan dengan teknik purposive sampling.

Instrumen yang digunakan dalam penelitian ini yaitu tes hasil belajar berupa pilihan ganda. Data yang diperoleh dari penelitian ini selanjutnya diolah dengan menggunakan uji statistik berupa uji normalitas (Chi-kuadrat), uji homogenitas dan uji hipotesis (uji t-dua pihak). 


\section{HASIL DAN PEMBAHASAN}

\section{Hasil Penelitian}

1. Tes Hasil Belajar Fisika

Posttest dilakukan dengan tujuan untuk mengetahui sejauh mana pengaruh model pembelajaran yang diberikan baik pada kelas eksperimen maupun kelas kontrol terhadap hasil belajar fisika siswa. Adapun hasil posttest siswa diperoleh rata-rata skor untuk kelas eksperimen sebesar 17,93 dengan standar deviasi 2,81 dan kelas kontrol sebesar 16,76 dengan standar deviasi 2,57 seperti terlihat pada Tabel 2 .

TABEL 2 DESKRIPSI SKOR TES HASIL BELAJAR SISWA UNTUK KELAS EKSPERIMEN DAN KELAS KONTROL

\begin{tabular}{ccc}
\hline Uraian & \multicolumn{2}{c}{ Tes Akhir (Posttest) } \\
\cline { 2 - 3 } & $\begin{array}{c}\text { Kelas eksperimen } \\
\text { (X IPA 2) }\end{array}$ & $\begin{array}{c}\text { Kelas kontol } \\
\text { kontrol } \\
(\text { X IPA 1) }\end{array}$ \\
\hline Sampel & 35 & 35 \\
\hline Skor minimum & 12 & 11 \\
\hline Skor maksimum & 23 & 22 \\
\hline Skor Rata-rata & 17,93 & 16,76 \\
\hline Standar Deviasi & 2,81 & 2,57 \\
\hline
\end{tabular}

2. Hasil Uji Normalitas

Pengujian normalitas data Postest pada penelitian ini menggunakan uji Chi-kuadrat dengan kriteria penerimaan $\chi_{\text {hitung }}^{2}<\chi_{\text {tabel }}^{2}$, taraf signifikan $a=0,05$, dan derajat kebebasan $\mathrm{dk}=$ $\mathrm{k}-3$. Hasil pengujian normalitas Posttest kelas eksperimen dan kelas kontrol dapat dilihat pada Tabel 3.

TABEL 3 HASIL UJI NORMALITAS DISTRIBUSI TES AKHIR PADA KELAS EKSPERIMEN DAN KELAS KONTROI

\begin{tabular}{ccc}
\hline Uraian & ikelas Eksperimen & Kelas Kontrol \\
\cline { 2 - 3 } & Tes Akhir & Tes Akhir \\
\hline Jumlah Siswa & 35 & 35 \\
\hline$\chi_{\text {hitung }}^{2}$ & 3,15 & 2,79 \\
\hline$\chi_{\text {tabel }}^{2}$ & 7,81 & 7,81 \\
\hline
\end{tabular}

Berdasarkan Tabel 3 terlihat bahwa nilai $\chi_{\text {hitung }}^{2}$ kelas eksperimen maupun kelas kontrol lebih kecil dari pada nilai $\chi_{\text {tabel }}^{2}$. Hasil ini menunjukkan bahwa data postest kelas eksperimen maupun kelas kontrol terdistribusi normal.
3. Hasil Uji Homogenitas Posttest

Uji homogenitas pada penelitian ini menggunakan uji statistik $\mathrm{F}$ dengan taraf signifikan $=0,05$. Uji homogenitas dilakukan untuk melihat apakah data berasal dari varians yang sama atau tidak, hal ini dapat dilihat pada Tabel 4.

TABEL 4 HASIL UJI HOMOGENITAS POSTTEST KELAS EKSPERIMEN DAN KELAS KONTROL

\begin{tabular}{ccc}
\hline Uraian & Posttest & Kontrol \\
\hline Nilai Varians & Eksperimen & 6,61 \\
\hline Nilai $F_{\text {hitung }}$ & 7,90 & \\
\hline Nilai $F_{\text {tabel }}(a=0,05)$ & & 1,20 \\
\hline Keputusan & 2,54 \\
\hline & Homogen \\
\hline
\end{tabular}

Berdasarkan hasil uji homogenitas pada Tabel 4 dengan taraf signifikan $(a=0,05)$, dari data tersebut terlihat bahwa $\mathrm{F}_{\text {hitung }}$ lebih kecil dari $\mathrm{F}_{\text {tabel }}$, maka berdasarkan kriteria pengambilan keputusan dapat disimpulkan bahwa tidak terdapat perbedaan varians antara kelas eksperimen dan kelas kontrol atau dengan kata lain varians antara kelas eksperimen dan kelas kontrol adalah sama atau homogen.
4. Uji Hipotesis (Uji-t)

Setelah terpenuhi uji normalitas dan homogenitas, maka dilakukan uji beda rata-rata (dua pihak) atau uji t. Uji ini digunakan untuk memastikan apakah hipotesis yang dilakukan dapat diterima atau tidak. Uji $t$ tersebut diperoleh berdasarkan tes akhir (posttest). 
Pengaruh Model Pembelajaran Kooperatif Tipe Stad Berbantuan Media Audio Visual Terhadap Hasil Belajar Fisika Siswa Kelas Xi SMA Negeri 1 Tikke Raya

TABEL 5 UJI BEDA RATA-RATA POSTTEST KELAS EKSPERIMEN DAN KELAS KONTROL

\begin{tabular}{|c|c|c|c|c|}
\hline Kelas & $\begin{array}{c}\text { Nilai rata-rata } \\
\bar{X}\end{array}$ & $t_{\text {hitung }}$ & $\begin{array}{c}t_{\text {tabel }} \\
(a=0,05)\end{array}$ & Keputusan \\
\hline Kelas Eksperimen & 17,93 & \multirow{2}{*}{1,82} & \multirow{2}{*}{1,67} & \multirow{2}{*}{$\mathrm{H}_{1}$ diterima } \\
\hline Kelas Kontrol & 16,76 & & & \\
\hline
\end{tabular}

Berdasarkan data Tabel 5 diketahui $t_{\text {hitung }} \geq$ $t_{\text {tabel }}$ atau $1,82 \geq 1,67$. Hal ini menunjukan bahwa nilai $t_{\text {hitung }}$ berada pada daerah penolakan $\mathrm{H}_{0}$, dengan demikian maka $\mathrm{H}_{1}$ diterima. Sehingga dapat disimpulkan bahwa terdapat perbedaan model pembelajaran Kooperatif Tipe STAD terhadap hasil belajar fisika siswa. Dengan kata lain, nilai hasil belajar kelas eksperimen lebih baik dibandingkan dengan kelas kontrol.

\section{Pembahasan}

Penelitian ini bertujuan untuk mengetahui apakah ada pengaruh hasil belajar fisika antara kelompok peserta didik yang mengikuti model pembelajaran kooperatif tipe STAD berbantuan media audio visual. Kegiatan pembelajaran pada penelitian ini dilakukan sebanyak 5 kali pertemuan terdiri dari 3 kali tatap muka di kelas dan 2 kali pertemuan untuk tes awal dan tes akhir dikedua kelas baik kelas kontrol maupun kelas eksperimen. Pada awal penelitian kedua kelas terlebih dahulu diberikan tes awal (pretest) untuk mengetahui bahwa kedua data berasal dari varians yang sama (homogen) atau memiliki kemampuan yang sama. Kemudian pada akhir penelitian kedua kelas diberikan tes akhir (posttest) untuk mengetahui kemampuan akhir siswa dan sebagai data analisis penelitian yang akan digunakan sebagai pembanding untuk melihat apakah terdapat perbedaan hasil belajar antara kedua kelas tersebut.

Berdasarkan pengujian hipotesis yang telah dilakukan menunjukkan bahwa pembelajaran menggunakan model kooperatif tipe STAD berbantuan media audio visual lebih baik dibandingkan dengan hasil belajar fisika siswa yang diajarkan menggunakan model direct intruction. Hal ini karena pada model pembelajaran kooperatif tipe STAD berbantuan media audio visual siswa dituntut lebih aktif berdiskusi dalam proses pembelajaran. Media audio visual mampu menampilkan gambar dan suara secara bersamaan sehingga siswa tidak hanya melihat atau mengamati, melainkan mendengarkan segala sesuatu yang divisualisasikan.

Pada kelas eksperimen peneliti menambahkan media audio visual dalam bentuk video pada tahap menyajikan informasi agar siswa tidak jenuh dalam belajar, menghemat waktu serta membuat siswa lebih aktif berdiskusi dalam tim. Pada tahap inilah yang membedakan suasana belajar serta nilai siswa kelas kontrol dan eksperimen pada posttest.

Pengkombinasian media audio visual dalam model pembelajaran kooperatif tipe STAD yang berupa video, membuat siswa akan lebih aktif dalam pembelajaran. Hal ini sesuai dengan penelitian yang dilakukan sebelumnya [9] yang menyatakan bahwa audio visual memungkinkan terjadinya komunikasi dua arah yakni terdapat interaksi timbal balik antara guru dan siswa dalam proses belajar mengajar sehingga siswa lebih aktif dalam proses pembelajaran. Dalam model pembelajaran ini siswa akan terlatih untuk bekerja sama, menghargai pendapat orang lain serta menekankan diri untuk aktif dalam tim.

\section{KESIMPULAN DAN SARAN}

\section{Kesimpulan}

Sebelum dilakukan penelitian, Peneliti memberikan tes awal kepada siswa untuk mengetahui kemampuan awal siswa. Berdasarkan hasil analisis data diperoleh ratarata skor posttest untuk kelas eksperimen yaitu sebesar 17,93 dan kelas kontrol yaitu sebesar 16,76 . Hasil ini menyatakan terdapat perbedaan hasil belajar kelas yang diterapkan model pembelajaran kooperatif tipe STAD berbantuan media audio visual dengan kelas yang diterapkan model pembelajaran langsung. Dengan demikian dapat disimpulkan bahwa terdapat pengaruh model pembelajaran kooperatif tipe STAD berbantuan media audio visual terhadap hasil belajar fisika siswa kelas XI SMAN 1 Tikke Raya.

\section{Saran}

Berdasarkan hasil penelitian yang telah diperoleh selama melakukan proses pembelajaran, maka penulis menyarankan :

1) Kepada guru bidang studi fisika agar dapat menerapkan model pembelajaran Kooperatif Tipe STAD berbantuan media audio visual pada materi-materi fisika untuk meningkatkan hasil belajar fisika siswa SMAN 1 Tikke Raya.

2) Bagi sekolah, model pembelajaran Kooperatif Tipe STAD berbantuan media audio visual dalam bentuk vidio ini, agar dapat dijadikan alternatif pembelajaran di sekolah untuk mata pelajaran lainnya.

3) Penelitian tentang penerapan model pembelajaran Kooperatif Tipe STAD berbantuan media audio visual dalam bentuk vidio dapat dilakukan pada pokok bahasan lain. 


\section{DAFTAR PUSTAKA}

[1]. Y. Sharan. "Cooperative Learning for Academic and Social Gains. Valued pedagogy, problematic practice". European Journal of Education, 45 (2), 300- 313. 2010.

[2]. D.W.Johnson." An Educational Psychology Success Story". Social interdependence theory and cooperative learning. Educational Research, 38(5), 365-37.2009.

[3]. Wibowo, Rahmat, Wahyudi \& Ngatman. Penerapan Model Kooperatif Tipe STAD dalam Peningkatan Pembelajaran Bangun Datar pada Siswa Kelas V SD. Kebumen: Kalam Cendekia.2016.

[4]. Isjoni. Cooperative Learning Efektifitas Pembelajaran Kelompok. Bandung: Alfabeta.2010.

[5]. Herdian. Model Pembelajaran STAD (Student Teams Achievement
Division).(Online),(Http://herdy07.wordpress. com/2009/04/22/modelpembelajaranstadstu dent-teams-achievement-division/).2009.

[6]. Nuryanti, Silviani, Triyono, Susiana, \& Saputri. Penerapan Model Kooperatif Tipe STAD dalam Peningkatan Pembelajaran Bilangan Pecahan Siswa Kelas IV Sekolah Dasar. Kebumen: Kalam Cendekia.2014.

[7]. Sukiman. Pengembangan Media Pembelajaran. Yogyakarta: Pustaka Insan Madani.2012.

[8]. M. Ibrahim. Pembelajaran Kooperatif. Surabaya: PT. Surabaya: UNESAUniversity Press.2000.

[9]. M.Hidayatul. Pengaruh Model Pembelajaran Kooperatif Tipe STAD Berbantuan Media Audio Visual untuk Meningkatkan Hasil Belajar Peserta Didik pada Mata Pelajaran Mengelolah Peralatan Kantor. Surakarta: Universitas Sebelas Maret.2017. 